\title{
Current landscape of palliative radiotherapy for non-small-cell lung cancer
}

\author{
Raphael Jumeau, Florent Vilotte, André-Dante Durham, Esat-Mahmut Ozsahin \\ Department of Radiation-Oncology, Lausanne University Hospital and University of Lausanne, Lausanne, Switzerland \\ Contributions: (I) Conception and design: R Jumeau, F Vilotte, AD Durham; (II) Administrative support: R Jumeau; (III) Provision of study materials \\ or patients: R Jumeau, F Vilotte, AD Durham; (IV) Collection and assembly of data: R Jumeau, F Vilotte, AD Durham; (V) Data analysis and \\ interpretation: All authors; (VI) Manuscript writing: All authors; (VII) Final approval of manuscript: All authors. \\ Correspondence to: Prof. Esat-Mahmut Ozsahin, MD, PhD. Department of Radio-Oncologie, Centre Hospitalier Universitaire Vaudois (CHUV), Rue \\ du Bugnon 46, CH-1011 Lausanne, Switzerland. Email: esat-mahmut.ozsahin@chuv.ch.
}

\begin{abstract}
Radiotherapy (RT) is a cornerstone in the management of advanced stage III and stage IV non-small-cell lung cancer (NSCLC) patients. Despite international guidelines, clinical practice remains heterogeneous. Additionally, the advent of stereotactic ablative RT (SABR) and new systemic treatments such as immunotherapy have shaken up dogmas in the approach of these patients. This review will focus on palliative thoracic RT for NSCLC but will also discuss the role of stereotactic radiotherapy, endobronchial brachytherapy $(\mathrm{EBB})$, the interest of concomitant treatments (chemotherapy and immunotherapy), and the role of RT in lung cancer emergencies with palliative intent.
\end{abstract}

Keywords: Lung cancer; radiotherapy; palliative intent

Submitted Apr 10, 2019. Accepted for publication Aug 13, 2019.

doi: $10.21037 /$ tlcr.2019.08.10

View this article at: http://dx.doi.org/10.21037/tlcr.2019.08.10

\section{Introduction}

Lung cancer is among the most deadly cancers worldwide (1); over half of newly diagnosed lung cancer patients die within one year of diagnosis, and 5-year survival is less than $18 \%$ (2). There are two main subtypes of lung cancer: non-small-cell lung cancer (NSCLC) and small-cell lung cancer (SCLC) representing $85 \%$ and $15 \%$ of all lung cancer, respectively (3).

More than $50 \%$ of patients with NSCLC are diagnosed with locally advanced (stage III) or metastatic (stage IV) disease (4). Among locally advanced NSCLC patients, almost $20 \%$ are unfit for curative treatment (5), and a similar proportion of metastatic patients will be treated for thoracic symptoms (6). Thus, palliative thoracic radiotherapy (RT) is one of the most common treatments in clinical practice, representing nearly $25 \%$ of all palliative RT courses (7). However, despite international consensus guidelines (8), clinical practice remains heterogeneous among clinicians (9).
This review will focus on palliative thoracic RT for NSCLC but will also discuss the role of stereotactic radiotherapy, endobronchial brachytherapy (EBB), the interest of concomitant treatments (chemotherapy and immunotherapy), and the role of RT in lung cancer emergencies.

\section{The palliative state: an evolving concept}

The purpose of palliative RT is to improve the patient's quality of life (QOL) by relieving or avoiding the occurrence of symptoms (10-12). For patients with poor Eastern Cooperative Oncology Group (ECOG) performance status (PS), treatment must be short and efficient with minimal side effects. Life expectancy must be estimated adequately using appropriate tools, such as mortality within 30 days, which has been suggested to be a useful clinical tool in palliative RT to avoid futile extensive fraction schedules (7). On the other hand, more aggressive treatments can avoid symptoms from local progression or delay initiation of a 
new systemic therapy at the cost of increased acute and/or late toxicities $(6,12,13)$. Several survival scores can be used for metastatic or locally advanced patients to help choose the best treatment (14-16).

In recent years, the concept of oligometastatic patients with low metastatic burden that experience remission or prolonged survival with ablative treatments has emerged. Gomez et al showed that local consolidative therapy for patients with three or fewer metastases from NSCLC that did not progress after initial systemic therapy improved progression-free survival compared with maintenance therapy alone (17). More recently, Gomez et al. published an update of the aforementioned trial that found an improved overall survival (OS) in patients who received local consolidative therapy (18). Similarly, Palma et al. showed in a randomized trial in cancer patients with up to five metastases that stereotactic ablative radiotherapy (SABR) to metastatic sites was associated to improved survival (19). Additionally, a multicentric ongoing study (SABR-COMET 10, NCT03721341) is evaluating the benefit of SABR for patients with 4-10 metastatic sites. Thus, as the palliative state may include a large variety of situations, adequate multidisciplinary evaluation of life expectancy has to be considered.

\section{Dose and fractionation in external beam radiotherapy (EBRT)}

Palliative EBRT is often used in the context of symptomatic lung cancer, metastatic disease and for locally advanced patients unfit to receive curative treatment. Palliative EBRT for lung cancer is a common and effective treatment leading to symptom reduction or relief in two thirds of irradiated patients and QOL improvement in one third of irradiated patients $(12,20,21)$.

Many clinical trials have tried to determine the best EBRT fractionation for palliation in lung cancer. Unfortunately, these studies were heterogeneous in terms of patient selection, reported outcomes and dose regimens. Among them, the majority of the reported treatments were hypofractionated: 10 Gy in 1 fraction, 16-17 Gy in 2 fractions, 20 Gy in 5 fractions, 30 Gy in 10 fractions, 40 Gy in two courses of 20 Gy (split course), and 39-45 Gy in 1315 fractions $(8,22-24)$. All of these schedules were shown to be effective for palliation.

A meta-analysis by Fairchild et al. (12) and a Cochrane review by Stevens et al. (22) tried to determine the best EBRT regimen by analyzing the results of 13 and 14 randomized controlled trials (RCT), respectively. No differences were found between dose schedules in terms of palliation efficacy; QOL was sometimes investigated, without any difference between dose schedules (25-38) (Table 1). Interestingly, in the study by Fairchild et al., the 2-year OS was significantly better for higher dose schedules (35 Gy $\mathrm{BED}_{\mathrm{BE} 0}$ or more) compared to lower dose schedules, with an OS of $26.5 \%$ vs. $21.7 \%$ for good PS patients, at the cost of more dysphagia due to esophageal toxicity $(20.5 \%$ vs. $14.9 \%$ ). However, in frail patients (ECOG PS 3-4) there was no advantage of high doses schedules.

In 2011, the American Society for Radiation Oncology (ASTRO) published clinical practice guidelines on palliative thoracic RT in lung cancer (8). The authors considered reserving higher dose regimens $(30 \mathrm{~Gy} / 10$ fractions or greater) for good PS patients, and those with sufficient life expectancy. For others patients, various shorter fractionation schedules (16-17 Gy/2 fractions, 20 Gy/5 fractions, etc.) provided similar symptomatic improvement, and are preferred in order to reduce treatment time (8). These recommendations remain in the updated 2018 guidelines (39).

With the improved survival associated with the advent of immunotherapy, an increasing number of patients can experiment local failure and subsequent complications because of insufficient local treatment. Therefore, increasing local control in this patient population could be of interest $(6,12,40)$. For these patients, modern EBRT techniques can reduce treatment toxicities. For example, Granton et al. showed that intensity-modulated radiotherapy (IMRT) can reduce esophagitis from 13\% to 2\% compared with traditional parallel-opposed fields for high dose treatments (41). Similarly, a randomized phase III study of palliative radiation of advanced tumors with intentional avoidance of the esophagus (PROACTIVE, NCT02752126) has recently completed his accrual.

In summary, EBRT is a cornerstone in the management of advanced stage III and stage IV NSCLC patients. High dose treatments $\left(\geq 35 \mathrm{~Gy}_{\mathrm{BED} 10}\right)$ are preferred for patients with good life expectancy while shorter dose schedules are recommended for poor ECOG PS patients.

\section{When is palliative RT indicated?}

Most patients diagnosed with locally advanced or metastatic NSCLC will suffer from or develop symptoms due to their malignancy. One of the issues is whether to irradiate an asymptomatic patient or wait for symptoms to appear. 
Table 1 Results of the main randomized controlled trials that compared palliative radiotherapy dose schedules for lung cancer patients

\begin{tabular}{|c|c|c|c|c|c|}
\hline Study & Type & Patients & Schedules & PS & Results \\
\hline Bezjak 2002 & RCT 1997-2001 & 230 & 20 Gy/5 F/1 w vs. 10 Gy/1 F & PS 0-3 & $\begin{array}{l}\text { MS } 6 \text { vs. } 4.2 \text { months }(P=0.0305) \text {; no } \\
\text { difference in toxicity or symptom; palliation } \\
\text { (daily diary); better QLC-C30 (pain score) } \\
\text { with } 5 \text { F }\end{array}$ \\
\hline Erridge 2005 & RCT 1988-1993 & 148 & $\begin{array}{l}30 \mathrm{~Gy} / 10 \mathrm{~F} / 2 \mathrm{w} \text { vs. } \\
10 \mathrm{~Gy} / 1 \mathrm{~F}\end{array}$ & PS 0-3 & $\begin{array}{l}\text { MS } 28.3 \text { vs. } 22.7 \text { w (ns); significant } \\
\text { improvement for chest pain, PS and } \\
\text { anxiety for } 10 \mathrm{~F}\end{array}$ \\
\hline Kramer 2005 & RCT 1999-2002 & 297 & $\begin{array}{l}30 \mathrm{~Gy} / 10 \mathrm{~F} / 2 \text { w vs. } \\
16 \mathrm{~Gy} / 2 \mathrm{~F} / 8 \text { days }\end{array}$ & PS 3-4 & $\begin{array}{l}\text { 1-year OS } 19.6 \% \text { vs. } 10.9 \%, P=0.03 \text {; no } \\
\text { difference in symptom palliation or toxicity; } \\
\text { longer palliation with } 10 \mathrm{~F}(\mathrm{P}<0.001)\end{array}$ \\
\hline MRC 1992 & RCT 1988-1989 & 235 & $\begin{array}{l}17 \mathrm{~Gy} / 2 \mathrm{~F} / 8 \text { days vs. } \\
10 \mathrm{~Gy} / 1 \mathrm{~F}\end{array}$ & PS 2-4 & $\begin{array}{l}\text { Good palliation efficacy (19-64\%), no } \\
\text { survival difference, more dysphagia with } \\
10 \text { Gy ( } 23 \% \text { vs. } 56 \%), 17 \text { Gy suggested to } \\
\text { be more effective except for hemoptysis }\end{array}$ \\
\hline MRC 1996 & RCT 1989-1992 & 509 & $\begin{array}{l}36-39 \text { Gy/12-13 F/2.5 w vs. } \\
17 \text { Gy/2 F/8 days }\end{array}$ & PS 0-2 & $\begin{array}{l}\text { Better palliation at } 2-3 \text { months with } 2 \\
\text { F; MS } 9 \text { vs. } 7 \text { months, OS } 2 \text { years } 12 \% \\
\text { vs. } 9 \%(\mathrm{P}=0.003) \text { in favour of } 13 \mathrm{~F} \text {; more } \\
\text { dysphagia, anorexia and nausea with } 13 \mathrm{~F}\end{array}$ \\
\hline $\begin{array}{l}\text { Senkus-Konefka } \\
2005\end{array}$ & RCT 1997-2000 & 100 & $\begin{array}{l}20 \text { Gy/5 F/1 w vs. } \\
16 \text { Gy/2 F/8 days }\end{array}$ & $P S \geq 1$ & $\begin{array}{l}\text { MS } 5.3 \text { vs. } 8 \text { months }(P=0.016) \text {; no } \\
\text { significant difference for toxicity or } \\
\text { symptom palliation }\end{array}$ \\
\hline Simpson 1985 & RCT 1973-1979 & 316 & $\begin{array}{l}40 \text { Gy/20 F/4 w vs. } \\
30 \text { Gy/10 F/2 w vs. } \\
40 \text { Gy/10 F/4 w split course }\end{array}$ & KPS $>60$ & $\begin{array}{l}\text { No difference in palliation rate, time to } \\
\text { response or survival }\end{array}$ \\
\hline Sundstrøm 2004 & RCT 1993-1998 & 407 & $\begin{array}{l}17 \text { Gy/2 F/8 days vs. } \\
42 \mathrm{~Gy} / 15 \mathrm{~F} / 3 \text { w vs. } \\
50 \mathrm{~Gy} / 25 \mathrm{~F} / 5 \mathrm{w}\end{array}$ & - & No difference in palliation or survival \\
\hline Teo 1988 & RCT 1982-1984 & 273 & $\begin{array}{l}45 \mathrm{~Gy} / 18 \mathrm{~F} / 3.5 \text { w vs. } \\
31.2 \mathrm{~Gy} / 4 \mathrm{~F} / 4 \mathrm{w}\end{array}$ & Any PS & $\begin{array}{l}\text { Palliation response } 71 \% \text { vs. } 54 \% \\
(P=0.012) \text {, no difference in toxicity or } \\
\text { survival }\end{array}$ \\
\hline
\end{tabular}

RCT, randomized controlled trial; Gy, Gray; F, fraction; w, weeks; PS, performance status (WHO); KPS, Karnofsky Performance Status scale; MS, median survival; OS, overall survival; PFS, progression-free survival. 
The randomized phase III trial by Sundstrøm et al. (42) compared different dose schedules in 407 stage III/IV NSCLC patients prospectively stratified according to the presence or the absence of tumour-related symptoms. Although non-symptomatic patients had a significantly higher median survival compared to symptomatic patients (11.8 vs. 6.0 months, respectively), non-symptomatic patients developed more symptoms while symptomatic patients experienced symptom relief in most scales (until week 14). In locally advanced NSCLC patients unsuitable for resection or curative RT, Falk et al. (43) showed that there was no benefit of immediate RT in minimally symptomatic NSCLC patients compared with delayed RT at time of symptom progression.

Another important issue is the duration of the palliation efficacy. In a study by Kramer et al., NSCLC patients were randomized to receive $16 \mathrm{~Gy}$ in two fractions or 30 Gy in 10 fractions; palliation was reached after five weeks for the 16 Gy group vs. seven weeks for the 30 Gy group, with a significantly longer duration of palliation efficacy for the latter schedule, persisting until the 22nd week (25). However, in the meta-analysis by Fairchild et al. (12) no difference was seen in terms of duration of symptom relief between high and low dose schedules.

Thus, the wait-and-see approach is actually the rule for palliative thoracic radiotherapy, instead of prevention; when patients become symptomatic short RT courses with low dose schedules should be preferred. This is questioned by the publication of Gomez et al. (17) where local consolidative therapy in non-symptomatic oligometastatic NSCLC patients improved progression-free survival compared to maintenance therapy alone.

\section{The growing role of stereotactic radiotherapy}

Recently, SABR or stereotactic body RT (SBRT) has appeared as a new tool in the management of palliative lung cancer patients. SABR consists generally of $1-5$ fractions of very high-dose RT ( $>6 \mathrm{~Gy} /$ fraction) delivered with stereotactic accuracy leading to high local control rates with low toxicity (44). Indeed, elderly and comorbid patients with lung cancer, unfit for curative treatments, are also less likely to receive long course RT due to concerns about comorbidity or frailty and, for this reason, RT is sometimes deferred until the development of symptoms.

Ablative treatments (surgery, SABR, or radiofrequency) are increasingly used in the management of multimetastatic cancer patients. SABR has proved to be safe and efficient for patients with early-stage NSCLC (45), and has been considered as a good option for elderly patients (46), patients with severe COPD (47), or patients with previous pneumonectomy (48). Given the convenience and high therapeutic ratio of SABR, there has been an increasing interest in using SABR in stage IV lung cancer.

To prove the value of SABR in oligometastatic patients, a randomized phase II multi-center trial for Stereotactic Ablative Radiotherapy for Comprehensive Treatment of Oligometastatic Tumors (SABR-COMET) has been conducted by Palma et al. (49). In this study, cancer patients with up to five metastases were randomized to either the standard of care (palliative RT to symptomatic sites with optional chemotherapy) versus SABR to all known metastatic sites with optional chemotherapy. Between February 2012 and August 2016, 99 patients were prospectively randomized, 33 in the palliative group and 66 in the SABR group, with a median follow-up of 25 months and 26 months, respectively. Median OS was 28 months in the control group $v s .41$ months in the SABR group $(\mathrm{P}=0.090)$ (19). This underlines the potential benefit of SABR for selected stage IV lung cancer patients.

In summary, SABR became the new standard in many institutions for early-stage lung cancer patients who are not eligible for surgery (50). On the other hand, the use of SABR in oligometastatic disease is increasing, and seems to be of interest in addition to systemic treatment to prolong the response to treatment. Additionally, data suggests an OS benefit that remains to be proven in upcoming phase III trials (51-53).

\section{EBB}

Although EBB still constitutes an interesting option for early-stage NSCLC, its use in palliative intent is less common. In the past decades, EBB has been jeopardized by interventional pulmonary procedures (argon plasma coagulation, cryotherapy, laser phototherapy, radiofrequency or direct tumor injection of chemotherapy) (54). EBB involves the placement of an endobronchial catheter (EC) in contact or in the close vicinity to the endobronchial malignancy to deliver local irradiation. The EC is placed by the pulmonologist during a flexible bronchoscopy and is, thereafter, connected to an afterloading device [mostly high dose rate (HDR)] containing the radioactive source.

Despite advances in HDR brachytherapy planning and delivery, EBB indications remain rare and controversial. Hence, due to its delayed effect, EBB is not indicated in 
case of complete bronchial obstruction and imminent suffocation (55). In these cases, interventional pulmonary procedures with an immediate effect are preferred. However, after recanalization, as the risk of re-obstruction is high, complementary techniques can be proposed, mostly using EBRT (56).

Stout et al. (57), in a RCT, compared palliative EBB to EBRT with QOL as primary end-point. They showed that QOL improvement was higher in the EBRT group compared to the EBB group (83 vs. 59\%; $\mathrm{P}=0.029$ ). Additionally, survival was better in the EBRT group (1- and 2-year survival: $38 \%$ vs. $22 \%$; and $10 \%$ vs. $2 \% ; \mathrm{P}=0.04$ ). Similarly, a Cochrane review published in 2012, concluded that EBRT alone is more effective for palliation than EBB alone (58). They underlined that for patients previously treated by EBRT who are symptomatic from recurrent endobronchial central obstruction, EBB may be considered in selected patients.

There is no evidence to suggest EBB in first intention as a palliative treatment for lung cancer. Its use can be evaluated on a case-by-case basis, especially for patients with endobronchial recurrence in a previously irradiated site.

\section{Concurrent chemotherapy (CC)}

In the 2011 ASTRO guidelines, the authors reported that there was no added benefit for the use of CC with EBRT in palliative intent for lung cancer patients (8). At that time, there was only one RCT, by Ball et al., that directly addressed this issue (59). This study showed that, in stage III lung cancer patients unsuitable for curative treatment, the addition of chemotherapy to palliative EBRT increased the overall response rate, at the cost of significant increased toxicity.

However, in 2018, an update of the previously cited guidelines was published with a focus on CC (39). Between 2011 and 2016, two RCTs investigated the role of CC for stage III NSCLC not eligible for curative treatment. In 2010, Nawrocki et al. (60) published a RCT enrolling incurable stage III NSCLC patients randomized between radiation alone (30 Gy in 10 fractions) $v s$. the same $\mathrm{RT}$ schedule delivered concurrently with the third cycle of a platinum based chemotherapy. Patients were defined as incurable based on a forced expiratory volume (FEV) in 1 second $\leq 40 \%$ of predicted or a tumor volume $>8 \mathrm{~cm}$. CC significantly improved the 1 - and 2-year OS rates $(25 \% v s$. $57 \%$ and $6 \%$ vs. 24\%). Grade 3-4 neutropenia was higher in the CC group (22\% vs. $0 \%$ ) but no other differences in grade 3 or more toxicity were observed.

The second RCT published in 2013 by Strøm et al. (61), was a phase III trial for incurable stage III NSCLC. Eligibility was defined as follows: adults of all ages with locally advanced, unresectable NSCLC stage III with one or more negative prognostic factors (tumour size $\geq 8 \mathrm{~cm}$, PS $\geq 2$, or weight loss of $>10 \%$ over the last six months). The randomization was made between chemotherapy alone (4 cycles of carboplatin and vinorelbine) vs. EBRT (42 Gy in 15 fractions) given concurrently with the second cycle of the same chemotherapy. CC significantly improved the 1and 2 -year OS rates (34\% vs. $53 \%$ and $7 \%$ vs. $28 \%$ ). CC significantly increased the grade 3 esophagitis rate $30 \%$ vs $1.5 \%$ ); however, QOL, social functioning, and physical functioning scores were better preserved in the CC group. Regarding these two articles, the RTOG recommends CC with palliative thoracic EBRT for incurable stage III NSCLC patients who are candidates for chemotherapy.

Both of these two previously cited studies have limitations. Perhaps, the most important limitation is the poorly defined patient populations. Indeed, there are no validated criteria to define which stage III NSCLC patients are eligible for curative treatment. All three RCTs showed increased acute morbidity associated with CC, mainly related to esophagitis. Toxicity concerns merit careful attention when patients are being treated with palliative intent.

To summarize, CC is indicated for NSCLC patients with advanced stage III disease ineligible for curative treatments (ECOG PS $\geq 2$, important weight loss or poor pulmonary function) but fit enough for chemotherapy. For all other palliative NSCLC patients, data remain insufficient to support CC with palliative thoracic EBRT (39).

\section{Concurrent immunotherapy}

Recently, immunotherapy has revolutionized the treatment of NSCLC (62). For example, inhibitors of the PD-1/ PD-L1 pathway have been proven to be superior to chemotherapy in the second-line setting, and even in the first-line setting for stage IV NSCLC patients with high expression of PD-L1 (63). Although it is hypothesized (based on preclinical data) that radiation can enhance the efficacy of immunotherapy even outside of the irradiated volume (= abscopal effect) (64), there are no recommendations on how these agents can be used safely in conjunction with radiation. Indeed, pneumonitis is one of the most feared complications of both immunotherapy and RT, and is 
known to be a potential cause of morbidity/mortality in NSCLC patients.

Radiation pneumonitis and radiation fibrosis are wellrecognized radiation-induced toxicities (65). Due to the potential immune mediated effects, the risk of pneumonitis or radiation pneumonitis during the combination of immunotherapy with radiation is a potential concern. Although the PACIFIC trial investigated immunotherapy (durvalumab) as an adjuvant treatment after definitive chemoradiotherapy with a good tolerance profile, data are limited (66). In a phase I study of ipilimumab in association with SABR for stage IV cancer patients, fourteen patients received SABR for lung lesions (67). None of the patients developed grade 2 or more pneumonitis. Thus, the authors concluded that combining SABR and ipilimumab was safe. Another example is a phase I study by TwymanSaint Victor et al. on patients with metastatic melanoma. Patients received ipilimumab 3-5 days following SABR to a metastatic lesion (68). Among the 22 patients treated, 10 had lung lesions irradiated (16-24 Gy in 2-3 fractions), and there were no dose-limiting toxicities observed. The PEMBRO-RT study compared the benefit of SABR $(3 \times 8 \mathrm{~Gy})$ to a single metastasis given within 7 days prior to the first cycle of pembrolizumab with pembrolizumab treatment alone, and preliminary data showed that the overall response rate at 12 weeks doubled from $19 \%$ to $41 \%$ in the irradiated group without increased toxicity (69).

To summarize, there are no clear recommendations on the combination of immunotherapy with radiation. The previous cited studies as well as ongoing studies (62) will hopefully provide better answers in the future.

\section{Emergencies}

Emergencies account for about 3\% of all RT courses. Among these, superior vena cava syndrome (SVCS) and hemoptysis are of particular importance for palliative lung RT (70).

SCVS is present in $10 \%$ of SCLC and $1.7 \%$ of NSCLC at diagnosis (20). It is mainly caused by an extrinsic compression of the superior vena cava by a right-sided thoracic tumor, or rarely by direct tumoral invasion. The diagnosis is mainly clinical, and always confirmed by computed tomography scan. Treatment must be multidisciplinary and will depend of the degree of emergency and the patient's global situation. It must include symptomatic (such as corticosteroids and oxygen) and cause- specific treatments. RT is an effective treatment for SVCS, with an overall symptomatic improvement for $70-80 \%$ of patients in 1-3 weeks. It seems to be more effective for SCLC with almost 77-95\% efficacy than for NSCLC with nearly $60 \%$ efficacy $(20,71,72)$. Armstrong et al. showed that high doses per fraction (3-4 Gy) yielded symptomatic relief in less than 2 weeks in $70 \%$ of the patients, compared to conventional-dose fractionation (2 Gy) with a response of $56 \%$ (73). Thus, hypofractionation with more than $3 \mathrm{~Gy}$ per fraction seems to be more effective (66).

Hemoptysis is a potentially life-threatening emergency defined by the expectoration of blood from the lower respiratory tract. It can occur in approximately $20 \%$ of patients with lung cancer, with $3 \%$ having terminal massive hemoptysis. The cause can be the tumor itself by local invasion or abnormal tumoral vasculature, tumoral shrinkage after a treatment, or due to a systemic therapy (anti-angiogenic or anticoagulant) (74,75). The type of treatment chosen must be obviously adapted to the clinical situation and the patient's shape. It is indicated to perform imaging studies such as CT-scans, angiography or bronchoscopy to support decision-making. EBRT is an efficient treatment to palliate hemoptysis in a small number of sessions, and can be effective within 24-48 h after the first session. The response rate is almost as high as $80 \%$, with some series reporting an efficiency of $97 \%$. No treatment scheme has been proved to be more effective than another in this indication; thus, hypofractionation is the rule in this particular indication $(12,20,70,74)$.

\section{Conclusions}

$\mathrm{RT}$ is still a cornerstone in the management of palliative NSCLC. For patients with good PS and/or life expectancy, high dose EBRT schedules are preferred. SABR is also a promising option for patients with low metastatic burden. CC in palliative intent is conceivable for patients suffering from advanced stage III NSCLC unfit for curative treatment.

\section{Acknowledgments}

None.

\section{Footnote}

Conflicts of Interest: The authors have no conflicts of interest 
to declare.

Ethical Statement: The authors are accountable for all aspects of the work in ensuring that questions related to the accuracy or integrity of any part of the work are appropriately investigated and resolved.

\section{References}

1. Siegel R, Ma J, Zou Z, et al. Cancer statistics, 2014. CA Cancer J Clin 2014;64:9-29.

2. Zappa C, Mousa SA. Non-small cell lung cancer: current treatment and future advances. Transl Lung Cancer Res 2016;5:288-300.

3. Sher T, Dy GK, Adjei AA. Small cell lung cancer. Mayo Clin Proc 2008;83:355-67.

4. Morgensztern D, Ng SH, Gao F, et al. Trends in Stage Distribution for Patients with Non-small Cell Lung Cancer: A National Cancer Database Survey. J Thorac Oncol 2010;5:29-33.

5. Baker S, Dahele $M$, Lagerwaard FJ, et al. A critical review of recent developments in radiotherapy for non-small cell lung cancer. Radiat Oncol 2016;11:115.

6. Dandekar VK, Young J, Kiel K, et al. Efficacy and Tolerability of Palliative Split-Course Thoracic Chemoradiotherapy for Symptomatic Non-Small Cell Lung Cancer. Am J Clin Oncol 2015;38:605-9.

7. Spencer K, Morris E, Dugdale E, et al. 30 day mortality in adult palliative radiotherapy--A retrospective population based study of 14,972 treatment episodes. Radiother Oncol 2015;115:264-71.

8. Rodrigues G, Videtic GM, Sur R, et al. Palliative thoracic radiotherapy in lung cancer: An American Society for Radiation Oncology evidence-based clinical practice guideline. Pract Radiat Oncol 2011;1:60-71.

9. Rodrigues G, Macbeth F, Burmeister B, et al. International practice survey on palliative lung radiotherapy: third international consensus workshop on palliative radiotherapy and symptom control. Clin Lung Cancer 2012;13:225-35.

10. Lutz ST, Jones J, Chow E. Role of radiation therapy in palliative care of the patient with cancer. J Clin Oncol 2014;32:2913-9.

11. Kelley AS, Meier DE. Palliative care--a shifting paradigm. N Engl J Med 2010;363:781-2.

12. Fairchild A, Harris K, Barnes E, et al. Palliative thoracic radiotherapy for lung cancer: a systematic review. J Clin Oncol 2008;26:4001-11.
13. Petrelli F, Ghidini A, Cabiddu M, et al. Addition of radiotherapy to the primary tumour in oligometastatic NSCLC: A systematic review and meta-analysis. Lung Cancer 2018;126:194-200.

14. Rades D, Käsmann L, Schild SE, et al. A Survival Score for Patients Receiving Palliative Irradiation for Locally Advanced Lung Cancer. Clin Lung Cancer 2016;17:558-62.

15. Sperduto PW, Yang TJ, Beal K, et al. Estimating Survival in Patients With Lung Cancer and Brain Metastases: An Update of the Graded Prognostic Assessment for Lung Cancer Using Molecular Markers (Lung-molGPA). JAMA Oncol 2017;3:827-31.

16. Alexander $\mathrm{M}$, Wolfe $\mathrm{R}$, Ball $\mathrm{D}$, et al. Lung cancer prognostic index: a risk score to predict overall survival after the diagnosis of non-small-cell lung cancer. $\mathrm{Br} \mathrm{J}$ Cancer 2017;117:744-51.

17. Gomez DR, Blumenschein GR, Lee JJ, et al. Local consolidative therapy versus maintenance therapy or observation for patients with oligometastatic non-smallcell lung cancer without progression after first-line systemic therapy: a multicentre, randomised, controlled, phase 2 study. Lancet Oncol 2016;17:1672-82.

18. Gomez DR, Tang C, Zhang J, et al. Local Consolidative Therapy Vs. Maintenance Therapy or Observation for Patients With Oligometastatic Non-Small-Cell Lung Cancer: Long-Term Results of a Multi-Institutional, Phase II, Randomized Study. J Clin Oncol 2019;37:1558-65.

19. Palma DA, Olson R, Harrow S, et al. Stereotactic ablative radiotherapy versus standard of care palliative treatment in patients with oligometastatic cancers (SABRCOMET): a randomised, phase 2, open-label trial. Lancet 2019;393:2051-8.

20. Kepka L, Olszyna-Serementa M. Palliative thoracic radiotherapy for lung cancer. Expert Rev Anticancer Ther 2010;10:559-69.

21. Støchkel Frank M, Schou Nørøxe D, Nygård L, et al. Fractionated palliative thoracic radiotherapy in non-small cell lung cancer - futile or worth-while? BMC Palliat Care 2018;17:15.

22. Stevens R, Macbeth F, Toy E, et al. Palliative radiotherapy regimens for patients with thoracic symptoms from nonsmall cell lung cancer. Cochrane Database Syst Rev 2015;1:CD002143.

23. Reinfuss M, Mucha-Małecka A, Walasek T, et al. Palliative thoracic radiotherapy in non-small cell lung cancer. An analysis of 1250 patients. Palliation of symptoms, tolerance and toxicity. Lung Cancer 2011;71:344-9. 
24. Metcalfe SK, Milano MT, Bylund K, et al. Split-Course Palliative Radiotherapy for Advanced Non-small Cell Lung Cancer. J Thorac Oncol 2010;5:185-90.

25. Kramer GW, Wanders SL, Noordijk EM, et al. Results of the Dutch National study of the palliative effect of irradiation using two different treatment schemes for nonsmall-cell lung cancer. J Clin Oncol 2005;23:2962-70.

26. Abratt RP, Shepherd LJ, Salton DG. Palliative radiation for stage 3 non-small cell lung cancer--a prospective study of two moderately high dose regimens. Lung Cancer 1995;13:137-43.

27. Bezjak A, Dixon P, Brundage M, et al. Randomized phase III trial of single versus fractionated thoracic radiation in the palliation of patients with lung cancer (NCIC CTG SC.15). Int J Radiat Oncol Biol Phys 2002;54:719-28.

28. Erridge SC, Gaze MN, Price A, et al. Symptom control and quality of life in people with lung cancer: a randomised trial of two palliative radiotherapy fractionation schedules. Clin Oncol (R Coll Radiol) 2005;17:61-7.

29. Nestle U, Nieder C, Walter K, et al. A palliative accelerated irradiation regimen for advanced non-smallcell lung cancer vs. conventionally fractionated 60 GY: results of a randomized equivalence study. Int J Radiat Oncol Biol Phys 2000;48:95-103.

30. Rees GJ, Devrell CE, Barley VL, et al. Palliative radiotherapy for lung cancer: two versus five fractions. Clin Oncol (R Coll Radiol) 1997;9:90-5.

31. Senkus-Konefka E, Dziadziuszko R, Bednaruk-Młyński $\mathrm{E}$, et al. A prospective, randomised study to compare two palliative radiotherapy schedules for non-small-cell lung cancer (NSCLC). Br J Cancer 2005;92:1038-45.

32. Simpson JR, Francis ME, Perez-Tamayo R, et al. Palliative radiotherapy for inoperable carcinoma of the lung: final report of a RTOG multi-institutional trial. Int J Radiat Oncol Biol Phys 1985;11:751-8.

33. Sundstrøm S, Bremnes R, Aasebø U, et al. Hypofractionated palliative radiotherapy (17 Gy per two fractions) in advanced non-small-cell lung carcinoma is comparable to standard fractionation for symptom control and survival: a national phase III trial. J Clin Oncol 2004;22:801-10.

34. Teo P, Tai TH, Choy D, et al. A randomized study on palliative radiation therapy for inoperable non small cell carcinoma of the lung. Int J Radiat Oncol Biol Phys 1988; 14:867-71.

35. Inoperable non-small-cell lung cancer (NSCLC): a Medical Research Council randomised trial of palliative radiotherapy with two fractions or ten fractions. Report to the Medical Research Council by its Lung Cancer Working Party. Br J Cancer 1991;63:265-70.

36. A Medical Research Council (MRC) randomised trial of palliative radiotherapy with two fractions or a single fraction in patients with inoperable non-small-cell lung cancer (NSCLC) and poor performance status. Medical Research Council Lung Cancer Working Party. Br J Cancer 1992;65:934-41.

37. Macbeth FR, Bolger JJ, Hopwood P, et al. Randomized trial of palliative two-fraction versus more intensive 13 -fraction radiotherapy for patients with inoperable non-small cell lung cancer and good performance status. Medical Research Council Lung Cancer Working Party. Clin Oncol (R Coll Radiol) 1996;8:167-75.

38. Reinfuss M, Glinski B, Kowalska T, et al. Radiotherapy for stage III, inoperable, asymptomatic small cell lung cancer. Final results of a prospective randomized study (240 patients). Cancer Radiother 1999;3:475-9.

39. Moeller B, Balagamwala EH, Chen A, et al. Palliative thoracic radiation therapy for non-small cell lung cancer: 2018 Update of an American Society for Radiation Oncology (ASTRO) Evidence-Based Guideline. Pract Radiat Oncol 2018;8:245-50.

40. Nieder C, Tollali T, Yobuta R, et al. Palliative Thoracic Radiotherapy for Lung Cancer: What Is the Impact of Total Radiation Dose on Survival? J Clin Med Res 2017;9:482-7.

41. Granton PV, Palma DA, Louie AV. Intentional avoidance of the esophagus using intensity modulated radiation therapy to reduce dysphagia after palliative thoracic radiation. Radiat Oncol 2017;12:27.

42. Sundstrøm S, Bremnes R, Brunsvig P, et al. Immediate or delayed radiotherapy in advanced non-small cell lung cancer (NSCLC)? Data from a prospective randomised study. Radiother Oncol 2005;75:141-8.

43. Falk SJ, Girling DJ, White RJ, et al. Immediate versus delayed palliative thoracic radiotherapy in patients with unresectable locally advanced non-small cell lung cancer and minimal thoracic symptoms: randomised controlled trial. BMJ 2002;325:465.

44. Kollar L, Rengan R. Stereotactic body radiotherapy. Semin Oncol 2014;41:776-89.

45. Timmerman RD, Paulus R, Pass HI, et al. Stereotactic Body Radiation Therapy for Operable Early-Stage Lung Cancer: Findings From the NRG Oncology RTOG 0618 Trial. JAMA Oncol 2018;4:1263-6.

46. Haasbeek CJ, Lagerwaard FJ, Antonisse ME, et al. Stage I nonsmall cell lung cancer in patients aged $>$ or $=75$ years: outcomes after stereotactic radiotherapy. Cancer 
2010;116:406-14.

47. Palma D, Lagerwaard F, Rodrigues G, et al. Curative treatment of Stage I non-small-cell lung cancer in patients with severe COPD: stereotactic radiotherapy outcomes and systematic review. Int J Radiat Oncol Biol Phys 2012;82:1149-56.

48. Haasbeek CJA, Lagerwaard FJ, de Jaeger K, et al. Outcomes of stereotactic radiotherapy for a new clinical stage I lung cancer arising postpneumonectomy. Cancer 2009;115:587-94.

49. Palma DA, Haasbeek CJA, Rodrigues GB, et al. Stereotactic ablative radiotherapy for comprehensive treatment of oligometastatic tumors (SABR-COMET): Study protocol for a randomized phase II trial. BMC Cancer 2012;12:305.

50. Senthi S, Lagerwaard FJ, Haasbeek CJ, et al. Patterns of disease recurrence after stereotactic ablative radiotherapy for early stage non-small-cell lung cancer: a retrospective analysis. Lancet Oncol 2012;13:802-9.

51. Cheung P. Stereotactic body radiotherapy for oligoprogressive cancer. Br J Radiol Br J Radiol 2016;89:20160251.

52. Macdermed DM, Weichselbaum RR, Salama JK. A rationale for the targeted treatment of oligometastases with radiotherapy. J Surg Oncol 2008;98:202-6.

53. Louie AV, Rodrigues G, Cheung P, et al. A review of palliative radiotherapy for lung cancer and lung metastases. J Radiat Oncol 2012;1:221-6.

54. Harris K, Puchalski J, Sterman D. Recent Advances in Bronchoscopic Treatment of Peripheral Lung Cancers. Chest 2017;151:674-85.

55. Hennequin C, Guillerm S, Wong S, et al. Endoluminal brachytherapy: Bronchus and oesophagus. Cancer Radiother 2018;22:367-71.

56. Spencer GM, Thorpe SM, Blackman GM, et al. Laser augmented by brachytherapy versus laser alone in the palliation of adenocarcinoma of the oesophagus and cardia: a randomised study. Gut 2002;50:224-7.

57. Stout R, Barber P, Burt P, et al. Clinical and quality of life outcomes in the first United Kingdom randomized trial of endobronchial brachytherapy (intraluminal radiotherapy) vs. external beam radiotherapy in the palliative treatment of inoperable non-small cell lung cancer. Radiother Oncol 2000;56:323-7.

58. Reveiz L, Rueda JR, Cardona AF. Palliative endobronchial brachytherapy for non-small cell lung cancer. Cochrane Database Syst Rev 2012;12:CD004284.

59. Ball D, Smith J, Bishop J, et al. A phase III study of radiotherapy with and without continuous-infusion fluorouracil as palliation for non-small-cell lung cancer. $\mathrm{Br}$ J Cancer 1997;75:690-7.

60. Nawrocki S, Krzakowski M, Wasilewska-Tesluk E, et al. Concurrent chemotherapy and short course radiotherapy in patients with stage IIIA to IIIB nonsmall cell lung cancer not eligible for radical treatment: results of a randomized phase II study. J Thorac Oncol 2010;5:1255-62.

61. Strøm HH, Bremnes RM, Sundstrøm SH, et al. Concurrent palliative chemoradiation leads to survival and quality of life benefits in poor prognosis stage III non-small-cell lung cancer: a randomised trial by the Norwegian Lung Cancer Study Group. Br J Cancer 2013;109:1467-75.

62. Evans T, Ciunci C, Hertan L, et al. Special topics in immunotherapy and radiation therapy: reirradiation and palliation. Transl Lung Cancer Res 2017;6:119-30.

63. Reck M, Rodríguez-Abreu D, Robinson AG, et al. Pembrolizumab versus Chemotherapy for PD-L1Positive Non-Small-Cell Lung Cancer. N Engl J Med 2016;375:1823-33.

64. Demaria $\mathrm{S}, \mathrm{Ng} \mathrm{B}$, Devitt $\mathrm{ML}$, et al. Ionizing radiation inhibition of distant untreated tumors (abscopal effect) is immune mediated. Int J Radiat Oncol Biol Phys 2004;58:862-70.

65. Tsoutsou PG, Koukourakis MI. Radiation pneumonitis and fibrosis: mechanisms underlying its pathogenesis and implications for future research. Int J Radiat Oncol Biol Phys 2006;66:1281-93.

66. Antonia SJ, Villegas A, Daniel D, et al. Durvalumab after Chemoradiotherapy in Stage III Non-Small-Cell Lung Cancer. N Engl J Med 2017;377:1919-29.

67. Tang C, Welsh JW, de Groot P, et al. Ipilimumab with Stereotactic Ablative Radiation Therapy: Phase I Results and Immunologic Correlates from Peripheral T Cells. Clin Cancer Res 2017;23:1388-96.

68. Twyman-Saint Victor C, Rech AJ, Maity A, et al. Radiation and dual checkpoint blockade activate non-redundant immune mechanisms in cancer. Nature 2015;520:373-7.

69. Theelen W, Lalezari F, de Vries J, et al. Randomized phase II study of pembrolizumab after stereotactic body radiotherapy (SBRT) versus pembrolizumab alone in patients with advanced non-small cell lung cancer: The PEMBRO-RT study. J Clin Oncol 2018;36:9023.

70. Christian E, Adamietz IA, Willich N, et al. Radiotherapy in oncological emergencies--final results of a patterns of care study in Germany, Austria and Switzerland. Acta 
Oncol 2008;47:81-9.

71. Talapatra K, Panda S, Goyle S, et al. Superior vena cava syndrome: A radiation oncologist's perspective. J Cancer Res Ther 2016;12:515-9.

72. Rowell NP, Gleeson FV. Steroids, radiotherapy, chemotherapy and stents for superior vena caval obstruction in carcinoma of the bronchus: a systematic review. Clin Oncol (R Coll Radiol) 2002;14:338-51.

Cite this article as: Jumeau R, Vilotte F, Durham AD, Ozsahin EM. Current landscape of palliative radiotherapy for non-smallcell lung cancer. Transl Lung Cancer Res 2019;8(Suppl 2):S192S201. doi: 10.21037/tlcr.2019.08.10
73. Armstrong BA, Perez CA, Simpson JR, et al. Role of irradiation in the management of superior vena cava syndrome. Int J Radiat Oncol Biol Phys 1987;13:531-9.

74. Johnstone C, Rich SE. Bleeding in cancer patients and its treatment: a review. Ann Palliat Med 2018;7:265-73.

75. Kvale PA, Simoff M, Prakash UB, et al. Lung cancer. Palliative care. Chest 2003;123:284S-311S. 